\title{
Adalimumab impact on fatigue measured by FACIT-F: a study of rheumatoid arthritis patients in Saudi Arabia
}

This article was published in the following Dove Press journal:

Open Access Rheumatology: Research and Reviews

17 October 2017

Number of times this article has been viewed

\author{
Nahed Janoudi' \\ Narges Omran² \\ Waleed Hussain ${ }^{3}$ \\ Hanan Al-osaimi ${ }^{4}$ \\ Matouqa Baamer \\ Muhammad Irfanullah \\ Siddiqui ${ }^{6}$ \\ Omar Fathaldin 7 \\ Hani Almoallim ${ }^{1,4,8}$ \\ 'Department of Medicine, Dr. Soliman \\ Fakeeh Hospital, Jeddah, ${ }^{2}$ Department \\ of Medicine, Alnoor General Hospital, \\ ${ }^{3}$ Department of Medicine, Heraa \\ General Hospital, ${ }^{4}$ Alzaidi Chair of \\ Research in Rheumatic Diseases, \\ Umm Al-Qura University, Makkah, \\ ${ }^{5}$ Department of Medicine, King \\ Abdulaziz Hospital \& Oncology \\ Center, Jeddah, ${ }^{6}$ Department of \\ Community Medicine and Public \\ Health, Faculty of Medicine, Umm \\ Al-Qura University, Makkah, \\ ${ }^{7}$ Department of Medicine, Faculty of \\ Medicine, King Abdulaziz University, \\ Jeddah, ${ }^{8}$ Department of Medicine, \\ Faculty of Medicine, Umm Al-Qura \\ University, Makkah, Saudi Arabia
}

Correspondence: Hani Almoallim Department of Medicine, Faculty of Medicine, Alzaidi Chair of Research in Rheumatic Diseases, Umm Al-Qura University, PO Box I82I, Jeddah 2I44I, Saudi Arabia

Tel +966505703935

Email hmmoallim@uqu.edu.sa
Objective: The objective of the study was to assess the effectiveness of adalimumab as a treatment for fatigue in patients with rheumatoid arthritis (RA).

Methods: Fatigue was monitored in patients with RA who were already on an adalimumab treatment regimen. Fatigue, general well-being, comorbidities, and disease activity were measured at baseline and $\sim 8,16$, and 24 weeks, thereafter.

Results: Significant reductions in fatigue scores and disease activity were observed from baseline to 6 months after. A predictive regression model of fatigue severity was proposed and was found to be significant, with RA disease activity as the most significant predictor of fatigue severity. Conclusion: This quasi-experimental study is a good starting point for research on the efficacy of adalimumab in treating fatigue in RA patients. The results here suggest that a randomized controlled trial assessing adalimumab as a treatment option for RA patients suffering from fatigue is warranted.

Keywords: rheumatoid arthritis, fatigue, adalimumab, disease activity, Saudi Arabia, FACIT-F

\section{Introduction}

Rheumatoid arthritis (RA) is an inflammatory joint disease that can lead to structural damage, disability, and alteration of quality of life. Up to $80 \%$ of patients with RA report fatigue, which has been infrequently assessed in published studies. ${ }^{1-3}$

It was observed that absence of fatigue characterizes disease remission. ${ }^{4}$ Qualitative studies highlight the importance people with RA attribute to fatigue. ${ }^{5,6}$ Between $40 \%$ and $80 \%$ of RA patients attending specialist clinics have clinically relevant fatigue, which is a feature of active disease. ${ }^{2-4,7}$

Although a consensus regarding the definition of fatigue is lacking, there is general agreement that it is a subjective and multidimensional phenomenon whose assessment requires the use of self-report methods. Fatigue can be defined as "a subjective state of overwhelming and sustained exhaustion and decreased capacity for physical and mental work that is not relieved by rest". ${ }^{8}$

The Patient Perspective Workshop at OMERACT 7 addressed the question of assessing the outcomes of intervention in RA from the perspective of those who experience the disease. Patient discussion groups clearly highlighted that fatigue is highly prevalent among RA patients; however, it is under-assessed by the treating physicians. ${ }^{9}$

The available biotherapies have demonstrated significant improvement in these outcomes, which dictates the necessity to revise the assessment of fatigue in RA patients and include fatigue relief as an important outcome of RA treatment. 
There is a lot of available data on the effects that biologics have on fatigue in RA patients, and there are also data about the role of adalimumab with respect to the same. ${ }^{10-12}$ However, to date there is no study that has assessed the impact of adalimumab, or anti-TNFs in general, on fatigue as the primary endpoint.

The aim of this investigator-initiated, non-interventional study was to obtain data on the effectiveness of adalimumab as a treatment for fatigue by measuring fatigue before, and 6 months after, the start of adalimumab subcutaneous (SC) therapy in Saudi Arabia. It is the authors' assertion that fatigue and health-related quality of life parameters are important aspects of RA that should be considered when evaluating a patient's overall response to therapy. This study will shed more light on the impact of biological therapy on the highly prevalent, under-assessed phenomenon of fatigue.

\section{Methods}

\section{Participants}

A sample size of 55 patients was estimated to provide $95 \%$ power to detect mean change in "The Functional Assessment of Chronic Illness Therapy-Fatigue" (FACIT-F) score assuming a non-normal distribution and a Type I $(\alpha)$ error probability of 0.05 , with a presumed medium effect size of 0.5 .

A total of 59 patients ( 53 females) were included in this study to allow for an attrition rate of $10 \%$. Patients were aged $21-73$ years $(M=45.25, S D=11.84)$. All patients had a diagnosis of adult-onset RA, and were not using adalimumab as part of their treatment regimen. For a summary of patient treatments prior to enrollment, see Table 1. Mean treatment duration was 6.12 months ( $\mathrm{SD}=8.33$ ). Patients were excluded from the study if they had a history of biologic treatment during the 6 months prior to enrollment, if they displayed symptoms suggestive of latent tuberculosis, or if they were participating in another clinical trial. Written informed consent was obtained from all patients before enrollment in the study. This study received ethical approval from the

Table I Patient therapy type prior to enrollment

\begin{tabular}{lll}
\hline Type of therapy & Frequency & Percent \\
\hline No therapy & 1 & 1.7 \\
Steroid alone & 5 & 8.5 \\
Steroid + MTX & 12 & 20.3 \\
Steroid + DMARD & 4 & 6.8 \\
MTX alone & 13 & 22 \\
MTX + DMARD & 20 & 33.9 \\
DMARD alone & 4 & 6.8 \\
\hline
\end{tabular}

Abbreviations: MTX, methotrexate; DMARD, disease-modifying antirheumatic drug. institutional review boards of Dr. Soliman Fakeeh Hospital and the Ministry of Health at Herra Hospital.

The percentage of patients without comorbid diagnoses at baseline was $45.8 \%$. The most common comorbid illness was thyroid dysfunction (13.6\%). In all, $6.8 \%$ of patients had comorbid osteoarthritis, 3.4\% had osteoporosis, and $1.7 \%$ had anemia, with $8.5 \%$ reporting other unspecified comorbidities. Extra-articular manifestations were present in just two patients. See Table 2 for a summary of participant demographic information.

\section{Design and procedure}

This was a quasi-experimental, investigator-initiated study, conducted using a prospective, single-country design. Patients were assessed at baseline (ie, study enrollment) and $\sim 8,16$, and 24 weeks, thereafter. Up to 3 follow-up visits were scheduled for each patient.

Information about concomitant medications taken for RA or any other disease was recorded in the case report form at study enrollment and during each follow-up visit, as was information on any comorbid diagnoses. Demographic information was collected at baseline, and fatigue and disease activity were measured at each time point. Information on serious adverse events was also collected at each time point.

\section{Materials}

The FACIT-F scale was developed from interviews with oncology patients and clinical experts to assess anemiaassociated fatigue. It is a patient-reported rating scale consisting of 13 items (statements) that yields a summed total score ranging between 0 and $52(52=$ less fatigue). FACIT-F has been used and validated in a range of patient groups, such as RA, Parkinson's disease (PD), various forms of cancer, and in the general population. ${ }^{13-15}$ FACIT-F is one of the most widely used fatigue scales today, ${ }^{16}$ and is available in 48 official language versions (www.facit.org) that have been produced according to rigorous standardized methodology.

FACIT-F fulfills criteria for a recommended scale for screening and suggested scale for severity rating. It is brief and has very good psychometric properties, including evidence for good reliability and internal and external validity in PD. FACIT-F is available in many languages including Arabic, and all translations have been produced in association with the developers of the scale using rigorous methodology.

In addition to FACIT-F, fatigue was also measured using the Fatigue Visual Analog Scale (VAS-F) before, and 6 months after, the start of adalimumab SC therapy. Disease activity was measured using the Disease Activity Score 
Table 2 Demographic information

\begin{tabular}{|c|c|c|c|c|c|c|c|c|}
\hline Variables & \multicolumn{8}{|l|}{ Categories } \\
\hline Sex & \multicolumn{4}{|l|}{$\begin{array}{l}\text { Male } \\
6(10.2 \%)\end{array}$} & \multicolumn{4}{|c|}{$\begin{array}{l}\text { Female } \\
53 \text { (89.8\%) }\end{array}$} \\
\hline Presence of EAM & \multicolumn{4}{|l|}{$\begin{array}{l}\text { Yes } \\
2(3.4 \%)\end{array}$} & \multicolumn{4}{|c|}{$\begin{array}{l}\text { No } \\
57 \text { (96.6\%) }\end{array}$} \\
\hline Marital status & \multicolumn{3}{|l|}{$\begin{array}{l}\text { Single } \\
5 \text { (8.5\%) }\end{array}$} & \multicolumn{3}{|l|}{$\begin{array}{l}\text { Married } \\
51 \text { (86.4\%) }\end{array}$} & \multicolumn{2}{|c|}{$\begin{array}{l}\text { Divorced } \\
3(5.1 \%)\end{array}$} \\
\hline Ethnicity & \multicolumn{3}{|l|}{$\begin{array}{l}\text { Arab } \\
53(89.8 \%)\end{array}$} & \multicolumn{3}{|l|}{$\begin{array}{l}\text { Caucasian } \\
4(6.8 \%)\end{array}$} & \multicolumn{2}{|c|}{$\begin{array}{l}\text { Asian } \\
2(3.4 \%)\end{array}$} \\
\hline Education level & \multicolumn{2}{|l|}{$\begin{array}{l}\text { <Secondary } \\
\text { II (I8.6\%) }\end{array}$} & \multicolumn{2}{|l|}{$\begin{array}{l}\text { Secondary } \\
21(35.6 \%)\end{array}$} & \multicolumn{2}{|c|}{$\begin{array}{l}\text { University } \\
26(44.1 \%)\end{array}$} & & $\begin{array}{l}>\text { University } \\
\mathrm{I}(1.7 \%)\end{array}$ \\
\hline \multirow[t]{2}{*}{ Occupation } & $\begin{array}{l}\text { House wife } \\
40(67.8 \%)\end{array}$ & $\begin{array}{l}\text { Student } \\
3(5.1 \%)\end{array}$ & $\begin{array}{l}\text { Teacher } \\
5(0.5 \%)\end{array}$ & $\begin{array}{l}\text { Labor wor } \\
4(6.8 \%)\end{array}$ & & $\begin{array}{l}\text { Clerk } \\
2(3.4 \%)\end{array}$ & $\begin{array}{l}\text { Unemployed } \\
3(5.1 \%)\end{array}$ & $\begin{array}{l}\text { Others } \\
2 \text { (3.4\%) }\end{array}$ \\
\hline & \multicolumn{4}{|l|}{ Mean \pm SD } & \multicolumn{4}{|c|}{$95 \% \mathrm{Cl}$ for mean } \\
\hline Age (years) & \multicolumn{4}{|l|}{$45.25 \pm I I .82$} & \multicolumn{4}{|c|}{$33.43-57.07$} \\
\hline Height (cm) & \multicolumn{4}{|l|}{$160.36 \pm 12.65$} & \multicolumn{4}{|c|}{$|47.7|-173.0 \mid$} \\
\hline Weight (kg) & \multicolumn{4}{|l|}{$77.10 \pm 19.24$} & \multicolumn{4}{|c|}{$57.86-96.34$} \\
\hline
\end{tabular}

Abbreviations: EAM, extra-articular manifestations; $\mathrm{Cl}$, confidence interval.

Calculator (DAS-28). Health status was measured using the General Health Visual Analog Scale (VAS-GH) and the Health Assessment Questionnaire (HAQ). Physiological measures included C-reactive protein (CRP), erythrocyte sedimentation rate (ESR), swollen joint count (SJC), and tender joint count (TJC).

\section{Results}

A paired sample $t$-test showed a significant reduction in FACIT-F mean scores from baseline $(\mathrm{M}=49.39, \mathrm{SD}=33.73)$ to 6 months after $(\mathrm{M}=41.09, \mathrm{SD}=32.56), t=6.29, p<0.001$. Similar results were found when comparing mean scores on VAS-F, with scores at baseline significantly higher $(\mathrm{M}=59.33$, $\mathrm{SD}=25.75)$ than 6 months later $(\mathrm{M}=36.44, \mathrm{SD}=17.09)$, $t=6.15, p<0.001$. There was also a significant reduction in disease activity from baseline $(\mathrm{M}=5.34, \mathrm{SD}=5.1)$ to 6 months after $(\mathrm{M}=3.18, \mathrm{SD}=1.13), t=3.34, p<0.01$.

A multiple regression analysis was conducted to predict FACIT-F scores based on the following predictor variables: CRP, HAQ, ESR, RA disease duration, VAS-GH General Health, age, VAS-F, SJC, final DAS-28, and TJC. The model was found to be a good statistical fit for the data and significantly predicted FACIT-F scores, $\mathrm{F}(10,28)=7.63, p<0.001, R^{2}=0.73$. However, when controlling for other variables in the model, the only variables that significantly predicted FACIT-F scores were final DAS-28 score and TJC, suggesting a degree of covariance between the variables in the model. Minimal clinically meaningful improvement was measured and tested for the difference in achiever/non-achiever. There was no significant difference between achiever and non-achiever $(p=0.068)$.

\section{Discussion}

Significant reductions in fatigue as measured by FACIT-F and VAS-F suggest that adalimumab treatment is effective in reducing symptoms of fatigue over an extended period of time. These results are indicative of the merit of adalimumab and other anti-TNFs in the treatment of fatigue in patients with RA. As this was a non-interventional study, it was not possible to compare patients receiving adalimumab treatment to a placebo control, or patients on other medication plans. The present study highlights the need for a randomized controlled trial to compare the efficacy of adalimumab to other anti-TNFs, and other options for treating fatigue in patients with RA.

An additional finding is that patients experienced a reduction in disease activity across the 6-month treatment period. This supports the findings of previous studies, which found that a significant proportion of RA patients achieved ACR20 and ACR50 responses after completing long-term adalimumab treatment plans, ${ }^{11,12}$ and studies that showed adalimumab treatment to have a positive impact on health status and quality of life for RA patients. ${ }^{10}$

The significance of the regression model suggests that several factors contribute to fatigue symptoms in RA patients. These include measures of general health, disease activity and duration, age, CRP, ESR, and TJC/SJC. The fact that TJC and disease activity were the only significant predictors when controlling for the other variables' effects may indicate a high degree of correlation between the other variables and disease activity. Indeed, if disease activity is high, it may be expected that patients would score lower on 
measures of general health, may be older, have elevated CRP and ESR, and may have a greater number of swollen/tender joints. This model suggests a significant predictive role of RA disease activity in severity of fatigue symptoms. This supports previous research which found that fatigue scores and disease activity decrease concurrently; however, it is not known whether this is a direct correlation or occurs as a result of reductions in other variables such as pain. ${ }^{17}$ While previous research efforts have shown that adalimumab works well to reduce disease activity, general health, and quality of life in RA patients, this is the first known study to examine the effectiveness of adalimumab in RA patients with fatigue as the primary focus. After 6 months of using adalimumab, RA patients demonstrated a significant reduction in feelings of fatigue. While this is a positive step toward identifying adalimumab as a good treatment option for RA patients suffering from fatigue, a randomized controlled trial is still needed to compare its efficacy to other anti-TFNs, other fatigue medications, and a placebo control.

\section{Acknowledgments}

This study was supported by grants from AbbVie. However, this funding source had no involvement in the design of the study or the collection, analysis, and interpretation of data. Moreover, they did not influence the writing of the report or the decision to submit for publication.

This study was supervised by Alzaidi Chair of Research in Rheumatic Diseases, Faculty of Medicine, Umm Al-Qura University, Makkah, Saudi Arabia.

We are thankful to Abdullah Harbi and Ahmed Bougous for entering the data.

\section{Disclosure}

The authors report no conflicts of interest in this work.

\section{References}

1. Kalyoncu U, Dougados M, Daurès JP, Gossec L. Reporting of patientreported outcomes in recent trials in rheumatoid arthritis: a systematic literature review. Ann Rheum Dis. 2009;68(2):183-190.
2. Belza BL, Henke CJ, Yelin EH, Epstein WV, Gilliss CL. Correlates of fatigue in older adults with rheumatoid arthritis. Nurs Res. 1993;42(2):93-99.

3. Wolfe F, Hawley DJ, Wilson K. The prevalence and meaning of fatigue in rheumatic disease. $J$ Rheumatol.1996;23(8):1407-1417.

4. Pinals RS, Masi AT, Larsen RA. Preliminary criteria for clinical remission in rheumatoid arthritis. Arthritis Rheum. 1981;24(10): 1308-1315.

5. Carr A, Hewlett S, Hughes R, et al. Rheumatology outcomes: the patient's perspective. J Rheumatol. 2003;30(4):880-883.

6. Ahlmén M, Nordenskiöld U, Archenholtz B, et al. Rheumatology outcomes: the patient's perspective. A multicentre focus group interview study of Swedish rheumatoid arthritis patients. Rheumatology (Oxford). 2005;44(1):105-110.

7. Belza BL. Comparison of self-reported fatigue in rheumatoid arthritis and controls. J Rheumatol. 1995;22(4):639-643.

8. Cella DF, Peterman A, Passik S, Jacobsen P, Breitbart W. Progress toward guidelines for the management of fatigue. Oncology (Williston Park). 1998;12(11A):369-377.

9. Kirwan, JR, Hewlett, SE, Heiberg, T, et al. Incorporating the patient perspective into outcome assessment in rheumatoid arthritis - progress at OMERACT 7. J Rheumatol. 2005;32(11):2250-2256.

10. Mittendorf T, Dietz B, Sterz R, Kupper H, Cifaldi MA, von der Schulenburg JM. Improvement and longterm maintenance of quality of life during treatment with adalimumab in severe rheumatoid arthritis. $J$ Rheumatol. 2007;34(12):2343-2350.

11. Weinblatt ME, Keystone EC, Furst DE, et al. Adalimumab, a fully human anti-tumor necrosis factor monoclonal antibody, for the treatment of rheumatoid arthritis in patients taking concomitant methotrexate: the ARMADA trial. Arthritis Rheum. 2003;48(1):35-45.

12. Keystone EC, Kavanaugh AF, Sharp JT, et al. Radiographic, clinical, and functional outcomes of treatment with adalimumab (a human anti-tumor necrosis factor monoclonal antibody) in patients with active rheumatoid arthritis receiving concomitant methotrexate therapy: a randomized, placebo-controlled, 52-week trial. Arthritis Rheum. 2004;50(5):1400-1411.

13. Hagell P, Höglund A, Reimer J, et al. Measuring fatigue in Parkinson's disease: a psychometric study of two brief generic fatigue questionnaires. J Pain Symptom Manage. 2006;32(5):420-432.

14. Cella D, Lai JS, Chang CH, Peterman A, Slavin M. Fatigue in cancer patients compared with fatigue in the general United States population. Cancer. 2002;94(2):528-538.

15. Cella D, Zagari MJ, Vandoros C, Gagnon DD, Hurtz HJ, Nortier JW. Epoetin alfa treatment results in clinically significant improvements in quality of life in anemic cancer patients when referenced to the general population. J Clin Oncol. 2003;21(2):366-373.

16. Minton $\mathrm{O}$, Stone P. A systematic review of the scales used for the measurement of cancer-related fatigue (CRF). Ann Oncol. 2009;20(1): $17-25$.

17. Pollard LC, Choy EH, Gonzalez J, Khoshaba B, Scott DL. Fatigue in rheumatoid arthritis reflects pain, not disease activity. Rheumatology (Oxford). 2006;45(7):885-889.
Open Access Rheumatology: Research and Reviews

\section{Publish your work in this journal}

Open Access Rheumatology: Research and Reviews is an international, peerreviewed, open access journal publishing original research, reports, editorials, reviews and commentaries on all aspects of clinical and experimental rheumatology in the clinic and laboratory including the following topics: Pathology, pathophysiology of rheumatological diseases; Investigation, treatment and

\section{Dovepress}

management of rheumatological diseases; Clinical trials and novel pharmacologi$\mathrm{cal}$ approaches for the treatment of rheumatological disorders. The manuscript management system is completely online and includes a very quick and fair peer-review system, which is all easy to use. Visit http://www.dovepress.com/ testimonials.php to read real quotes from published authors. 